\title{
RUMAH SINGGAH KANKER ANAK DENGAN TERAPI PALIATIF
}

\author{
Felicia Hansen ${ }^{1)}$, Suryono Herlambang ${ }^{2)}$ \\ 1)Program Studi S1 Arsitektur, Fakultas Teknik, Universitas Tarumanagara, feliciahansen189@gmail.com \\ 2) Program Studi S1 PWK, Fakultas Teknik, Universitas Tarumanagara, suryonoh@ft.untar.ac.id
}

\begin{abstract}
Abstrak
Rumah sakit yang dapat menangani anak penderita kanker umumnya berada di kota besar, contohnya Jakarta. Bagi anak-anak penderita kanker yang berasal dari luar daerah dan keluarganya tidak mampu membiayai rawat inap di rumah sakit, mereka terpaksa melakukan perjalanan pulang pergi yang memakan banyak waktu dan biaya transportasi. Selain perawatan medis, para penderita kanker juga membutuhkan perawatan paliatif; yang merupakan pendekatan sistem perawatan terpadu untuk meningkatkan kualitas hidup pasien dan keluarga mereka ketika menghadapi penyakit terminal yang membahayakan jiwa, dengan memberikan dukungan spiritual dan psikososial; mulai saat diagnosis ditegakkan sampai pada akhir hidup pasien kanker. Solusi dari isu tersebut adalah merancang rumah singgah kanker anak yang memiliki fasilitas terapi paliatif dengan acuan desain yang ramah anak dan sesuai dengan kebutuhan anak-anak penderita kanker, serta letaknya dekat dengan rumah sakit rujukan untuk kanker anak. Perancangan rumah singgah kanker anak dengan terapi paliatif ini bertujuan untuk merancang rumah singgah yang tidak hanya sebagai tempat tinggal alternatif bagi anak-anak penderita kanker, namun juga sebagai tempat rekreasi, relaksasi, dan edukasi. Pembentukan dan pengaturan ruang arsitektural dari rumah singgah mengacu pada keterkaitan antara aktivitas manusia dan lingkungannya. Konsep desain dari perancangan tapak yaitu Urban Oasis. Bangunan seakan-akan berada di tengah-tengah hutan yang rindang dengan sungai kecil yang mengelilinginya. Di sini, selain mendapatkan dukungan spiritual dan psikososial, anak-anak juga dapat menyalurkan hobi mereka dalam bidang seni dan musik, melepas stress setelah menjalani perawatan medis melalui interaksi dengan hewan dan alam, juga bermain dan belajar bersama.
\end{abstract}

Kata Kunci: arsitektur keseharian; lingkungan pemulihan; masa depan berhuni; perawatan paliatif; rumah singgah

\begin{abstract}
Hospitals that can treat pediatric cancer are usually located in big cities, for example Jakarta. For children with cancer who come from outside the region and their families are unable to pay for hospitalization, they are forced to travel back and forth which takes a lot of time and transportation fees. Apart from medical care, the children with cancer also need palliative care, which is an integrated care system approach to improve the quality of life for patients and their families when facing life-threatening terminal illnesses by providing spiritual and psychosocial support from the time the diagnosis is made to the end of life for cancer patients. The solution is to design a childhood cancer lodging that has palliative therapy facilities with child-friendly and appropriate design references, and is located close to a referral hospital for pediatric cancer. The design of the lodging aims to make a shelter that is not only served as "the second home" for children with cancer, but also as a place for recreation, relaxation, and education. The formation and arrangement of architectural spaces of the lodging refers to the connection between human activities and their environment. The design concept of the site is Urban Oasis. The building seems to be in the middle of a forest with a small river that surrounds it. Here, apart from getting spiritual and psychosocial support, children can also take up their hobbies in the arts and music, relieve stress after undergoing medical treatment through interactions with animals and nature, as well as play and learn together.
\end{abstract}

Keywords: childhood cancer lodging; everydayness architecture; future dwelling; healing environment; palliative care 


\section{PENDAHULUAN}

\section{Latar Belakang}

Isu yang diangkat dalam perancangan adalah kanker anak di Indonesia. Jenis kanker yang umumnya menyerang anak-anak yaitu: Leukimia, Limfoma, Osteosarkoma, Rhabdomiosarkoma, Retinoblastoma, Willm's tumor, dan Neuroblastoma. Menurut data Riskesdas tahun 2013, prevalensi kanker anak umur 0-14 tahun sebesar 16.291 kasus. Berdasarkan data RS Kanker Dharmais 2010-2013, jumlah kasus baru dari kanker anak terus meningkat rata-rata sekitar $19 \%$ tiap tahunnya.

Namun sayang, kanker anak masih belum banyak mendapat perhatian dari masyarakat dan pemerintah dibandingkan dengan jenis kanker lainnya, seperti kanker payudara dan kanker serviks. Hal itu dapat terlihat dari masih sedikitnya rumah singgah kanker yang dikhususkan untuk anak-anak, padahal kebutuhan ruang dan aktivitas pada anak-anak berbeda dengan orang dewasa.
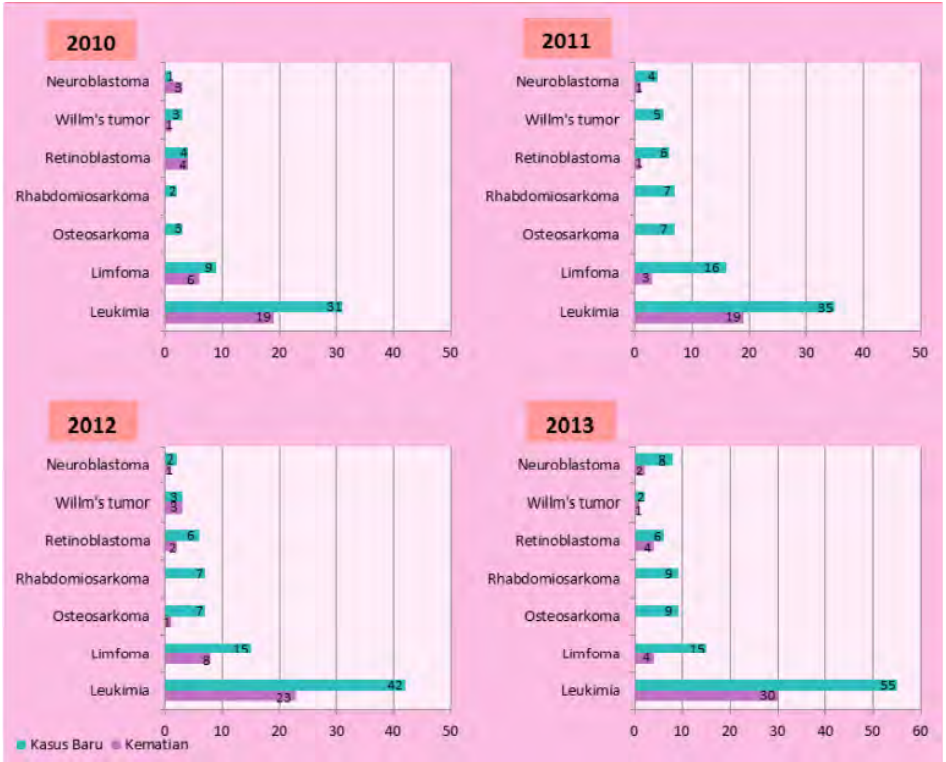

Gambar 1. Jumlah Kasus Baru dan Jumlah Kematian Akibat Penyakit Kanker pada Anak di RS Kanker Dharmais, Tahun 2010-2013

Sumber: Instalasi Deteksi Dini dan Promosi Kesehatan RS Kanker Dharmais, 2010-2013.

Rumah sakit yang dapat menangani anak penderita kanker umumnya berada di kota besar, contohnya Jakarta. Bagi anak-anak penderita kanker yang berasal dari luar daerah dan keluarganya tidak mampu membayar biaya rawat inap di rumah sakit, mereka terpaksa melakukan perjalanan pulang pergi yang memakan banyak waktu dan biaya transportasi. Selain perawatan medis, para penderita kanker juga menbutuhkan perawatan paliatif, yaitu pendekatan sistem perawatan terpadu untuk meningkatkan kualitas hidup pasien dan keluarga mereka ketika menghadapi penyakit terminal yang membahayakan jiwa dengan memberikan dukungan spiritual dan psikososial mulai saat diagnosis ditegakkan sampai pada akhir hidup pasien kanker. Solusi dari isu tersebut adalah merancang rumah singgah kanker anak yang memiliki fasilitas terapi paliatif dengan acuan desain yang ramah anak dan sesuai dengan, serta letaknya dekat dengan rumah sakit rujukan untuk kanker anak.

Selain sebagai tempat tinggal alternatif karena biaya sewa yang murah dan dekat dengan rumah sakit rujukan, manfaat lain dari tinggal di rumah singgah bagi anak dan orang tuanya yaitu mendapatkan dukungan dari sesama pasien, seperti berbagi tentang pengalaman 
mengatasi gejala penyakit, nyeri, dan dukungan emosional lainnya. Hal tersebut dapat meningkatkan motivasi dalam menjalani pengobatan antar pasien.

Perawatan paliatif adalah pendekatan sistem perawatan terpadu untuk meningkatkan kualitas hidup pasien dan keluarga ketika menghadapi penyakit terminal yang membahayakan jiwa, dengan memberikan dukungan spiritual dan psikososial; mulai saat diagnosis ditegakkan sampai pada akhir hidup pasien kanker. Tujuan lain dari perawatan paliatif adalah memberikan pasien kesempatan untuk tinggal di rumah pasien selama yang pasien inginkan dan tetap menjaga biaya kesehatan yang dikeluarkan pasien serendah mungkin.

\section{Rumusan Permasalahan}

Permasalahan yang dapat diidentifikasi sebagai pertimbangan dalam perancangan rumah singgah kanker anak adalah: merancang bangunan yang berorientasi pada kebutuhan anak penderita kanker dan acuan desain bangunan yang dapat membantu mempercepat pemulihan, serta dapat menampung kegiatan berhuni sekaligus kegiatan terapi paliatif (terapi seni - musik - hewan - sensorik).

\section{Tujuan}

Tujuan dari perancangan rumah singgah kanker anak dengan terapi paliatif ini adalah:

- Merancang rumah singgah kanker anak yang tidak hanya sebagai tempat tinggal alternatif bagi anak-anak penderita kanker, namun juga sebagai tempat rekreasi, relaksasi, dan edukasi.

- Merancang rumah singgah kanker anak yang dapat membantu pemulihan anak-anak penderita kanker melalui terapi paliatif dengan dukungan spiritual dan psikososial

\section{KAJIAN LITERATUR}

Dalam bukunya "The Concept of Dwelling", Christian Norberg-Schulz mengungkapkan bahwa kata "dwelling" memiliki makna lebih mendalam dari sekadar atap yang menaungi di atas kepala kita dan sejumlah meter persegi ruang yang kita miliki. Dia membaginya menjadi 3 arti, yaitu:

a. Ruang di mana kita bertemu dengan orang lain untuk bertukar produk, ide, dan perasaan, pada makna ini kita akan mendapatkan pengalaman kehidupan sebanyak mungkin.

b. Mencapai kesepakatan dengan orang lain di mana kita akan dihadapkan untuk dapat menerima seperangkat nilai-nilai umum di masyarakat.

c. Ketika kita telah menjadi diri kita dengan memiliki dunia kecil pilihan kita sendiri.

Dapat dikatakan ketiga arti itu masing-masing sebagai pengertian "berhuni" secara kolektif, publik, dan pribadi. Hal itu dijabarkan karena konsep "berhuni" harus dapat memberikan kontribusi menyeluruh dalam kehidupan manusia di bumi.

\section{Pendekatan Desain}

Elements of Healing Environment

Menurut Michael L.Knecht dalam "Optimal Healing Environment" (2010), terdapat 5 elemen yang dibutuhkan pasien untuk mempercepat pemulihan: Options and choices, Access to social support, Connection to nature, Positive distractions, dan Elimination of environmental stress.

Secara garis besar; pasien perlu diberi kebebasan untuk memilih atas kehendaknya sendiri (tidak atas paksaan) untuk mengurangi stress, dukungan dari orang-orang terdekat dan lingkungannya, interaksi dengan alam yang dapat membantu mempercepat pemulihan, kegiatan-kegiatan positif yang dapat mengalihkan pikiran mereka tentang penyakit yang diderita, dan lingkungan yang tenang serta nyaman. 
Residential Hospice Environment Design

Menurut Stephen Verderber dalam makalah "Residential Hospice Environments" (2014), terdapat 8 pertimbangan desain arsitektur dalam membangun sebuah rumah singgah pasien: Site and context, Arrival spaces, Communal spaces, Private spaces, Transitional spaces, Nature and connectivity, Caregiver support, dan The total hospice environment.

Secara garis besar; dalam memilih tapak untuk membangun sebuah rumah singgah diperlukan pertimbangan mengenai fasilitas pendukung di sekitar lokasi, peraturan lahan, terbebas dari kebisingan, keamanan bagi calon penghuni, dan desain bangunan yang sesuai iklim. Sebuah desain rumah singgah pasien sebaiknya dapat menghilangkan kesan arsitektur sebuah rumah sakit, ramah bagi pengguna kursi roda, dan bagian entrance yang dapat melindungi dari hujan. Zona kegiatan dalam rumah singgah pasien harus dikategorikan sesuai tingkat privasinya. Unsur alam seperti pencahayaan dan material alami harus ada di dalam bangunan sebagai bagian dari terapi pikiran pasien (Theraserialization). Selain fasilitas untuk pasien, fasilitas bagi para perawat dan pekerja juga harus disediakan (contoh: area penginapan perawat). Yang terakhir; manajemen fasilitas rumah singgah pasien harus mencakup pemeliharaan, keamanan, lansekap, pemanfaatan sistem hemat energi dan mematuhi kode keselamatan.

\section{Carefree Design}

Dalam buku "Poetics of Architecture", Anthony C. Antoniades mengemukakan pendapatnya mengenai hubungan perasaan sukacita dengan kreativitas seseorang. Perasaan sukacita (carefree) adalah keadaan dimana seseorang merasa tidak khawatir, cemas, dan tertekan. Hal tersebut menyebabkan seseorang dapat mendedikasikan dirinya secara total untuk usahausaha kreatif. Keadaan yang tidak gembira (tertekan) dianggap sering menghalangi kreatifitas.

John Simonds mengatakan bahwa karakteristik ruang merupakan kualitas abstrak yang akan mempengaruhi respon emosi maupun psikologi pemakainya. Menurutnya, karakteristik ruang yang mengapresiasikan konsep kegembiraan itu adalah sebagai berikut: pola dan bentuk halus mengalir, gerakan dan irama terlihat pada struktur, sedikit batasan, warna hangat dan cerah, serta cahaya berkelap-kelip.

Untuk mendukung perasaan sukacita dan kreativitas pada anak-anak penderita kanker, maka ruang pada rumah singgah kanker anak sebaiknya memiliki desain sebagai berikut:

- Mengunakan garis atau bentukan dinamis dalam ruang.

- Menghadirkan pengalaman ruang yang berbeda.

- Penggunaan warna hangat dan cerah.

- Memberikan kemudahan sirkulasi dan interaksi.

- Memenuhi persyaratan karakteristik fungsi ruang.

\section{METODE PERANCANGAN}

Penulis menggunakan acuan metode desain dari dua buku, yang ditulis oleh Agustinus Sutanto dan Philip Plowright. Dalam buku "Peta Metode Desain" (2020) yang ditulis oleh Agustinus Sutanto, dikatakan bahwa terdapat empat wilayah penting yang menjadi pelingkup dari setiap metode desain yang digunakan oleh arsitek, yaitu: Dunia Seni Dunia Sains Dunia Perilaku dan Dunia Lingkungan. Dari keempat wilayah tersebut, penulis memilih Dunia Perilaku, yang terbagi menjadi 4 jenis arsitektur: Spatial perception, Keseharian, Fenomenologi, dan Tempat ketiga. Dari keempat jenis arsitektur tersebut, penulis memilih Arsitektur Keseharian. Berdasarkan pernyataan pada buku tersebut, arsitektur keseharian tidak membangun melalui ide-ide abstrak (ide-ide yang mengacu pada nilai estetika dan ditransfer menjadi gambar 
arsitektural), melainkan melihat kenyataan sebagai bahan referensi bertindak. Melalui sudut pandang keseharian, arsitektur menjadi sebuah usaha untuk melihat kenyataan tentang bagaimana manusia menggunakan ruang guna memenuhi kebutuhan hidupnya dan memunculkan ruang-ruang baru yang dibutuhkannya.

Philip Plowright dalam buku "Revealing Architectural Design: Methods, Frameworks and Tools" (2014), metode desain dapat dibagi menjadi 3 landasan, yaitu: Pattern-based Framework, Force-based Framework, dan Concept-based Framework.

Dari ketiga landasan desain tersebut, penulis memilih Force-based Framework. Keterkaitan antara aktivitas manusia dan lingkungan merupakan kekuatan yang saling berhubungan dalam suatu lingkungan. Kekuatan tersebut lah yang digunakan untuk membentuk dan mengatur ruang arsitektural agar tercapai kenyamanan maksimum, efisiensi, serta kualitas terbaik untuk fungsi dan habitat. Program pembangunan dibentuk melalui hubungan yang kompleks antara kebutuhan spasial, penggunaan ruang, pola sosial, kondisi iklim, urutan proses, hubungan ruang publik-privat, dan kualitas lingkungan seperti cahaya, angin, dan area terbuka.

Dari kedua acuan metode desain di atas, dapat disimpulkan bahwa perancangan rumah singgah kanker ini didasari oleh kebutuhan ruang-ruang baru untuk anak-anak penderita kanker dalam menjalani kegiatan sehari-hari dan bagaimana mereka akan menggunakannya. Selain itu, keterkaitan aktivitas penghuni dengan lingkungannya juga menjadi dasar ide perancangan rumah singgah kanker anak.

\section{DISKUSI DAN HASIL}

\section{Pemilihan Tapak}

Di Jakarta, terdapat beberapa rumah sakit besar milik pemerintah dan swasta yang biasa menjadi rumah sakit rujukan kanker anak, diantaranya: RSCM, RS Kanker Dharmais, RSAB Harapan Kita, RSUP Persahabatan, dan RSUP Fatmawati. Di sekitar RSCM, RS Kanker Dharmais, RSAB Harapan Kita dan RSUP Persahabatan terdapat 9 rumah singgah yang didirikan oleh organisasi peduli kanker seperti YKAKI, YOAI, dan CISC; sedangkan di sekitar RSUP Fatmawati belum terdapat rumah singgah kanker (terutama untuk anak-anak).
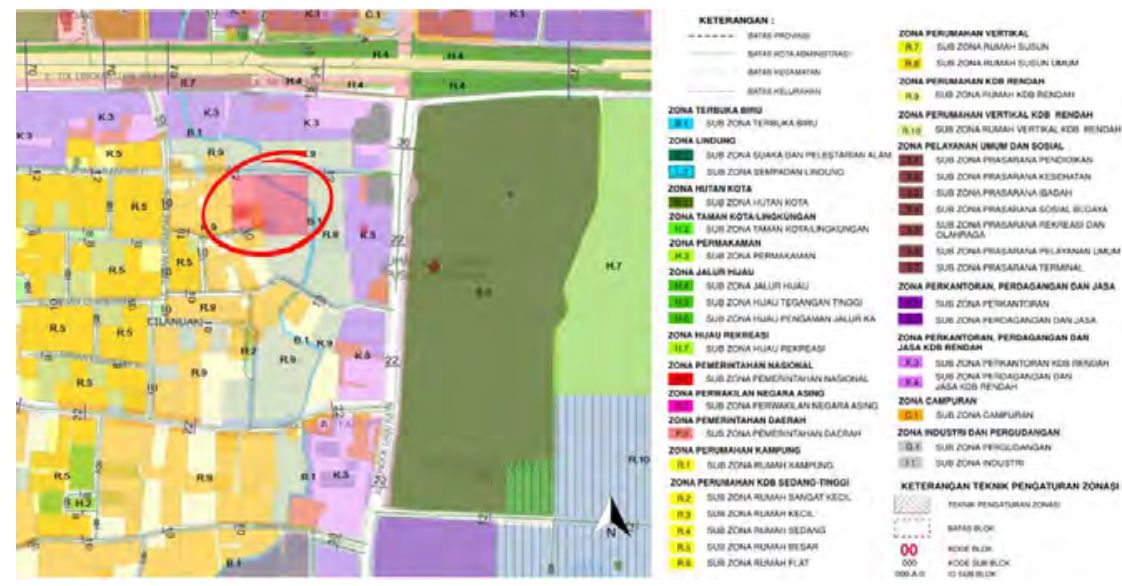

Gambar 2. Peta Lokasi Tapak

Sumber: jakartasatu.jakarta.go.id, diakses pada tanggal 20 Agustus 2020 (dengan penambahan)

Tapak terpilih berjarak \pm 700 m dari RSUP Fatmawati dan \pm 350 m dari Halte MRT Fatmawati (via JI. H. Ismail dan JI. Taman Cilandak Raya). Selain itu, di sekitar tapak juga terdapat berbagai fasilitas umum seperti: 
- Apotek Guardian ( $\pm 500 \mathrm{~m}$ dari tapak)

- Indomaret ( $\pm 600 \mathrm{~m}$ dari tapak)

- ATM Center ( $\pm 500 \mathrm{~m}$ dari tapak)

- Masjid An Najm ( $\pm 400 m$ dari tapak)

- Gereja St. Stefanus ( $\pm 1 \mathrm{~km}$ dari tapak)

- Pasar Mede ( $\pm 1.3 \mathrm{~km}$ dari tapak)

- Pasar Becek Pondok Labu ( $\pm 3 \mathrm{~km}$ dari tapak)
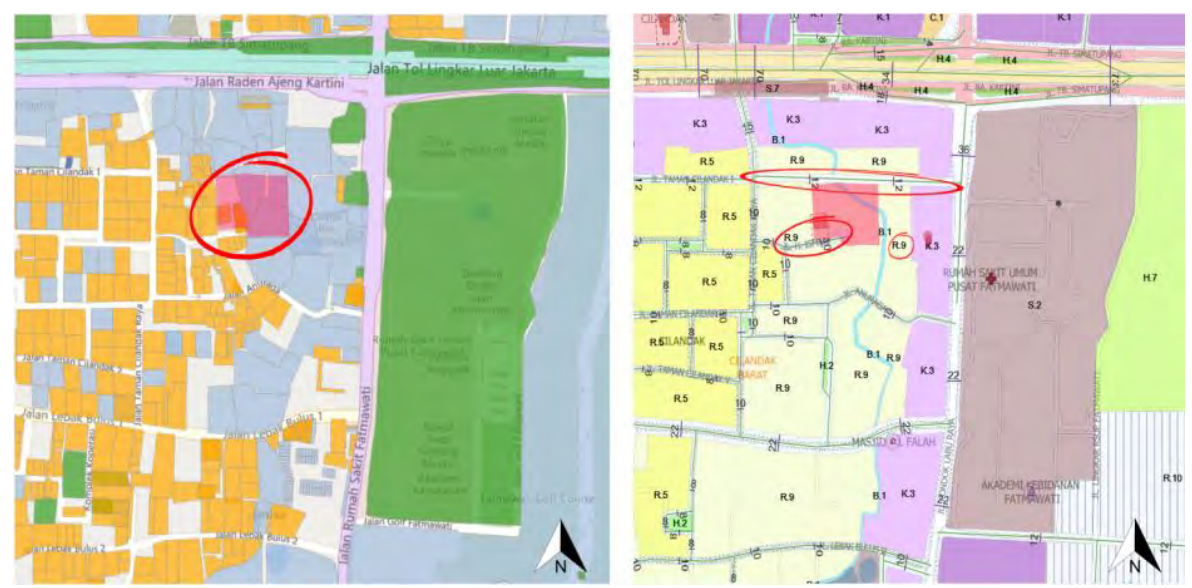

Gambar 3. Pembentukan Kavling Tapak

Sumber: bhumi.atrbpn.go.id dan jakartasatu.jakarta.go.id diakses pada tanggal 20 Agustus 2020 (dengan penambahan)

Bentuk tapak merupakan hasil dari pertimbangan pembagian kavling pada Peta BPN \& Peta Rencana Kota. Pada Peta Rencana Kota, terdapat pelebaran jalan dan pembuatan jalan baru di depan tapak terpilih. Fungsi saat ini tapak berupa lahan kosong dan satu rumah. Pada Peta Rencana Kota, tapak akan menjadi bagian dari Sub Zona Rumah KDB Rendah (R9) dan terdapat jalan baru yang menghubungkan JI.Taman Cilandak Raya dengan JL. RS Fatmawati Raya selebar $12 \mathrm{~m}$. J. H. Ismail yang saat ini memiliki lebar $\pm 4 \mathrm{~m}$ akan diperbesar menjadi $10 \mathrm{~m}$. Tapak terpilih ini memiliki luas 7.250,143m2 dan memiliki aturan RDTR (Rencana Detail Tata Ruang) sebagai berikut:

- Zona = Perumahan KDB Rendah

- $\quad$ Tipe $=\mathrm{R}$ (Sub Zona R9)

- $\mathrm{KDB} 30=2.175 \mathrm{~m}^{2}$

- $\mathrm{KDH} 45=3.262 .5 \mathrm{~m}^{2}$

- $\mathrm{KLB} 0.9=6.525 \mathrm{~m}^{2}$

- $\quad \mathrm{KTB} 3=21.750 \mathrm{~m}^{2}$

\section{Konsep Rancangan}

Sesuai dengan pendekatan desain Healing Environment, yang mengutamakan koneksi dengan alam sebagai cara untuk meringankan rasa sakit dan stress pada penderita kanker; konsep desain dari perancangan tapak yaitu Urban Oasis. Bangunan seakan-akan berada di tengahtengah hutan yang rindang dengan sungai kecil yang mengelilinginya. Dengan begitu, area hijau lebih mendominasi tapak dibandingkan bangunan. Selain itu, penderita kanker juga membutuhkan lingkungan yang tenang (jauh dari kebisingan) dan pencahayaan matahari yang optimal namun tidak panas. Oleh karena itu, posisi bangunan berada di tengah-tengah tapak agar kebisingan dari lingkungan sekitar dan panas matahari dapat teredam oleh pepohonan.

Bangunan untuk rumah singgah kanker anak harus terlihat lembut, ringan, dan jauh dari kesan 
sebuah rumah sakit. Penggunaan warna pada bangunan dapat membantu memberi kesan ceria namun tetap lembut. Konsep dari bentuk bangunan yaitu telur. Telur adalah simbol kehidupan dan pengharapan. Bentuk geometri yang mewakilkan poin-poin tersebut adalah oval. Oval memiliki bentuk yang tak bersudut (lembut), memberi kesan keterhubungan, kebersamaan, dan perlindungan.

\section{Konsep Zonasi Tapak dan Bangunan}

Dari hasil analisis aksesibilitas, potensi view, arah matahari, dan kebisingan lingkungan tapak; maka diusulkan zonasi horizontal dan vertikal seperti berikut ini.

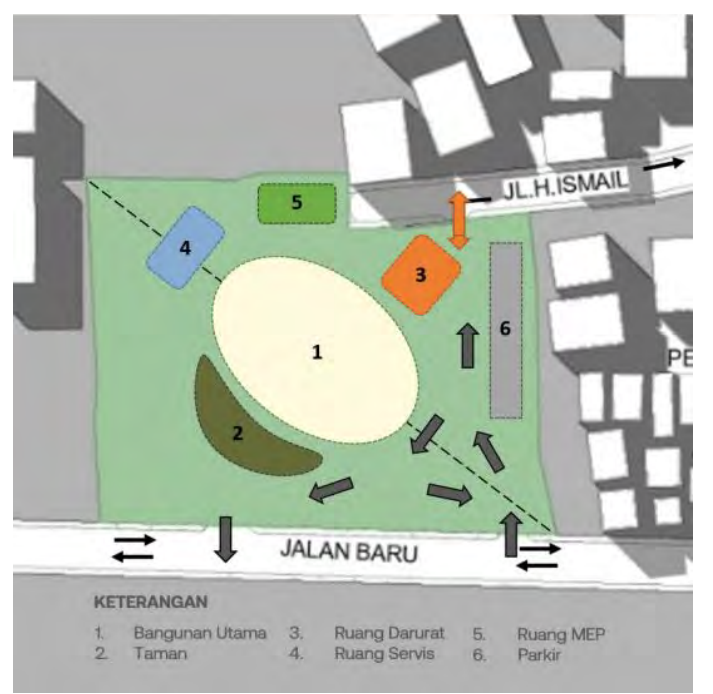

Gambar 4. Zonasi Horizontal Tapak Sumber: Penulis, 2020

Akses masuk dan keluar tapak di jalan baru dipisahkan agar sirkulasi pengunjung yang datang dan keluar tidak saling bersilangan, sehingga sirkulasi kendaraan pengunjung dalam tapak lebih teratur. Pengunjung dapat memilih untuk keluar ke arah Jl. H. Ismail atau ke arah Jalan Baru. Selain itu, dari arah Jl. RS Fatmawati Raya menuju tapak, pengunjung akan melewati akses keluar tapak terlebih dahulu untuk masuk ke dalam tapak. Tujuannya adalah agar pengunjung dapat mempersiapkan diri untuk belok ke arah akses masuk tapak, sehingga kemungkinan pintu masuk tapak terlewati oleh pengunjung sangat kecil.

Karena tapak dikelilingi oleh lingkungan perumahan \& komersil, tapak tidak memiliki potensi view ke luar. Dengan begitu potensi view harus dibuat di dalam tapak (sekeliling bangunan). Di sisi lain, bangunan pada tapak akan terlihat jelas dari Jalan Baru; oleh karena itu fasad sisi depan bangunan harus terlihat lebih dinamis dibanding sisi belakang. Area yang menarik seperti taman juga cocok diletakkan di sisi depan sebagai main attraction bagi pengunjung, sedangkan area servis dapat diletakkan di sisi belakang.

Sumber kebisingan utama pada tapak berasal dari jalan, sisanya berasal dari perumahan dan area komersil. Untuk menghindari kebisingan tersebut, bangunan ditempatkan di tengahtengah tapak serta dikelilingi pepohonan untuk meredam kebisingan. Zona hunian tidak boleh berhadapan langsung dengan jalan untuk menghindari kebisingan tingkat tinggi, sedangkan zona kegiatan komunal tidak masalah jika diletakkan di sisi depan karena kegiatan komunal tidak membutuhkan suasana yang hening. 


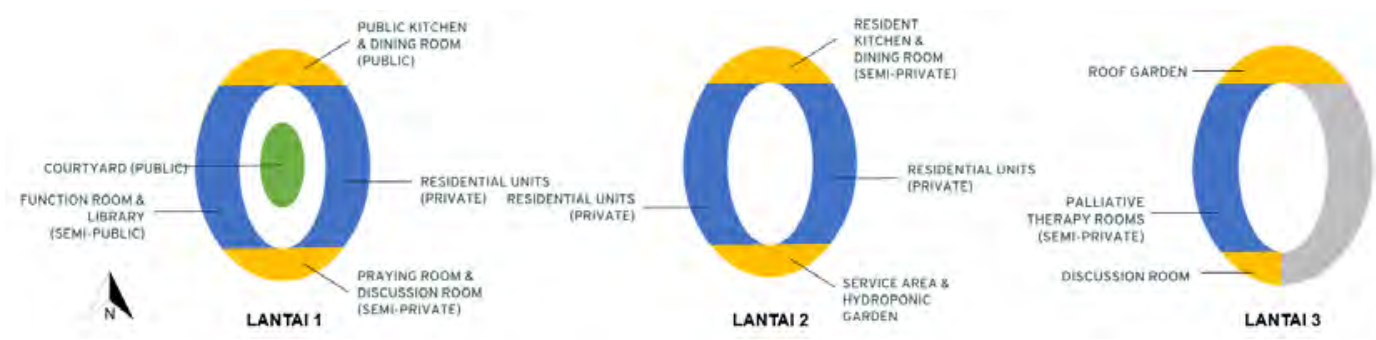

Gambar 5. Zonasi Horizontal \& Vertikal Bangunan

Sumber: Penulis, 2020

Karena sinar matahari pagi sangat dibutuhkan oleh penghuni, sisi timur dapat dimanfaatkan sebagai zona hunian. Sinar matahari sore di sisi barat terasa panas, oleh karena itu sisi barat lebih cocok dimanfaatkan sebagai zona servis dan zona kegiatan penghuni yang tidak membutuhkan view ke luar untuk mengurangi kebutuhan bukaan (jendela). Bagian bangunan yang menghadap sisi utara \& selatan dapat memiliki bukaan yang luas untuk sirkulasi pencahayaan matahari \& udara ke dalam bangunan.

\section{Konsep Bentuk Bangunan}

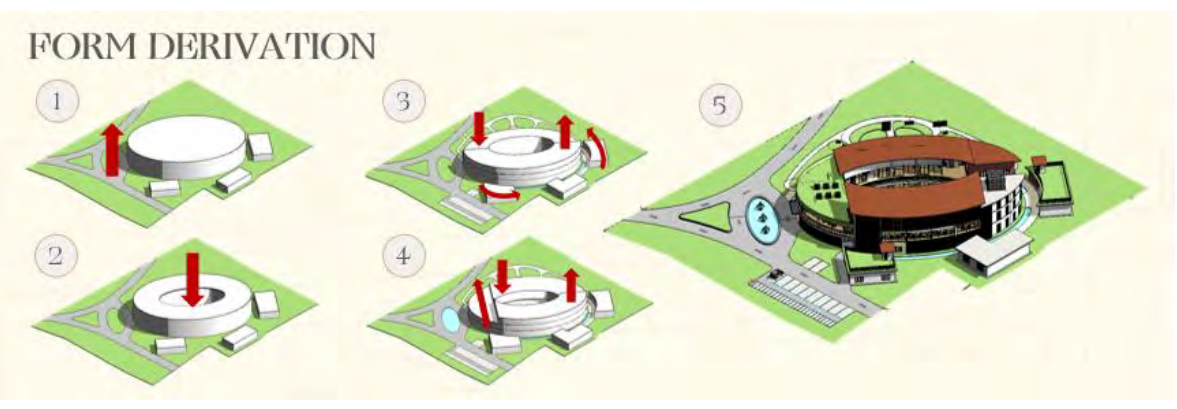

Gambar 6. Transformasi Gubahan Massa Bangunan Sumber: Penulis, 2020

Gubahan massa bangunan utama berawal dari bentuk oval sederhana, yang kemudian diberi lubang di bagian tengah. Setelah itu dibuat perbedaan jumlah lantai antara bagian bangunan yang menghadap sisi timur dan menghadap sisi barat. Pada bagian bangunan yang menghadap sisi timur memiliki ketinggian 2 lantai, sedangkan pada bagian bangunan yang menghadap sisi barat memiliki ketinggian 3 lantai. Hal itu bertujuan agar ketika cahaya matahari berasal dari sisi timur, maka seluruh area hunian akan mendapatkan sinar matahari. Balkon hunian, selasar, dapur bersama dan area fasilitas bersama pun juga mendapatkan cahaya matahari secara optimal. Ketika cahaya matahari berada tepat di tengah, area courtyard akan mendapat cahaya optimal. Ruang-ruang di sekitar courtyard dan selasar juga akan mendapatkan cahaya secara optimal sehingga tidak memerlukan lampu di siang hari. Ketika cahaya matahari berasal dari sisi barat yang relatif lebih panas, area hunian tidak tersorot langsung oleh matahari karena terhalang oleh bangunan sisi barat yang lebih tinggi.

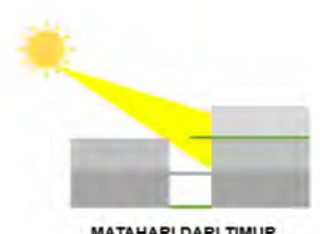

MATAHARI DARI TIMUR

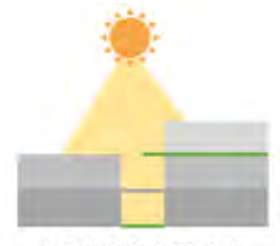

MATAHARI DARI TENGAH

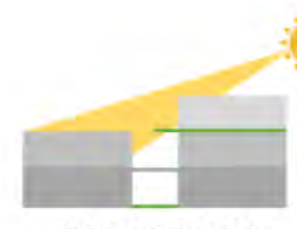

MATAHARI DARI BARAT

Gambar 7. Cahaya Matahari terhadap Bangunan

Sumber: Penulis, 2020 


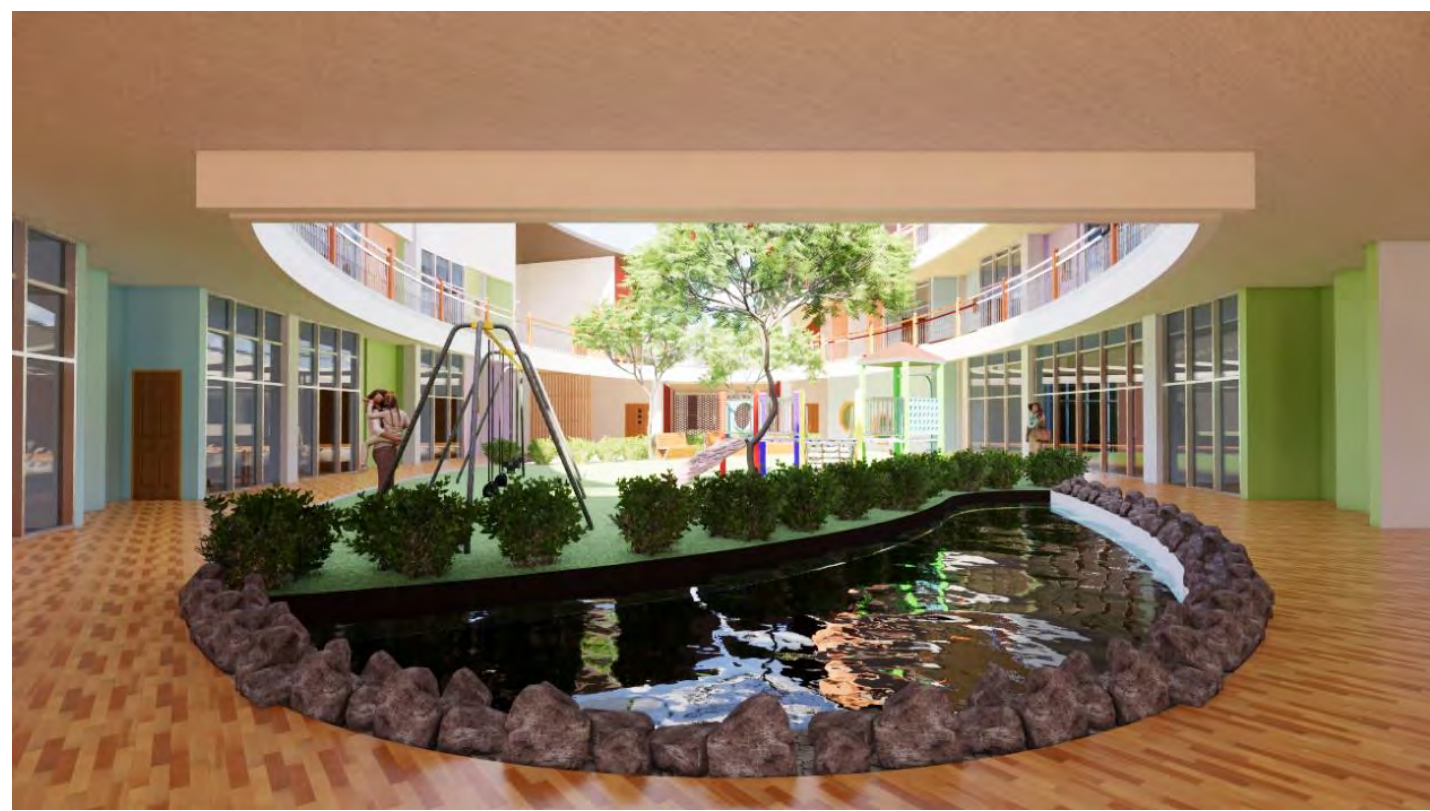

Gambar 8. Courtyard (Outdoor Playground)

Sumber: Penulis, 2020

Taman Sensorik diletakkan di sisi timur agar pertumbuhan vegetasi menjadi optimal. Posisi Taman Sensorik tersebut juga memberikan keuntungan bagi area hunian, yaitu sebagai penyaring panas sinar matahari dan main view dari teras/balkon hunian. Bentuk awal bangunan-bangunan pendukung (Emergency Unit, Servis, MEP) adalah kotak sederhana. Kemudian pada sisi bangunan-bangunan pendukung yang berdekatan dengan bangunan utama berubah mengikuti lengkungan dari dinding terluar bangunan utama. Area parkir berada di dekat bangunan utama dan bangunan Emergency Unit untuk mempermudah akses pengunjung dan penghuni. Pada sisi depan bangunan utama ketinggiannya adalah 2,5 lantai; dengan lantai tertingginya berfungsi sebagai roof garden sekaligus kanopi dari area main entrance.

Atap bangunan Emergency Unit dan servis juga berfungsi sebagai roof garden agar siluet bangunan menyatu dengan area terbuka hijau di sekitarnya. Ruang-ruang paling atas pada sisi kiri dan kanan dari bangunan utama menggunakan penutup atap spandek dengan kemiringan 5 o, sehingga siluet bangunan terlihat dinamis dengan kemiringan atap yang tidak drastis. Selain itu, penggunaan atap dapat mengurangi luas permukaan bagian atas bangunan yang menyerap panas sinar matahari. Ruang paling atas sisi belakang-kanan menggunakan atap dak beton. Atap tersebut dimanfaatkan sebagai area rooftank. Posisi tersebut memudahkan sistem distribusi pemipaan rooftank.

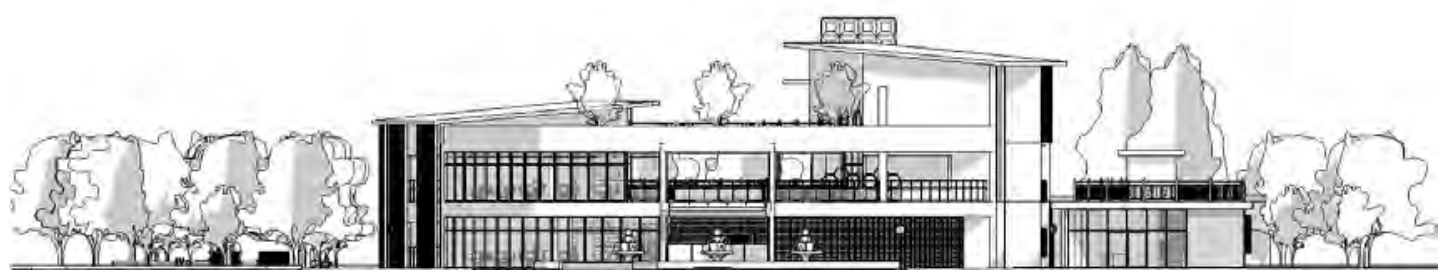

Gambar 9. Tampak Depan Bangunan

Sumber: Penulis, 2020 


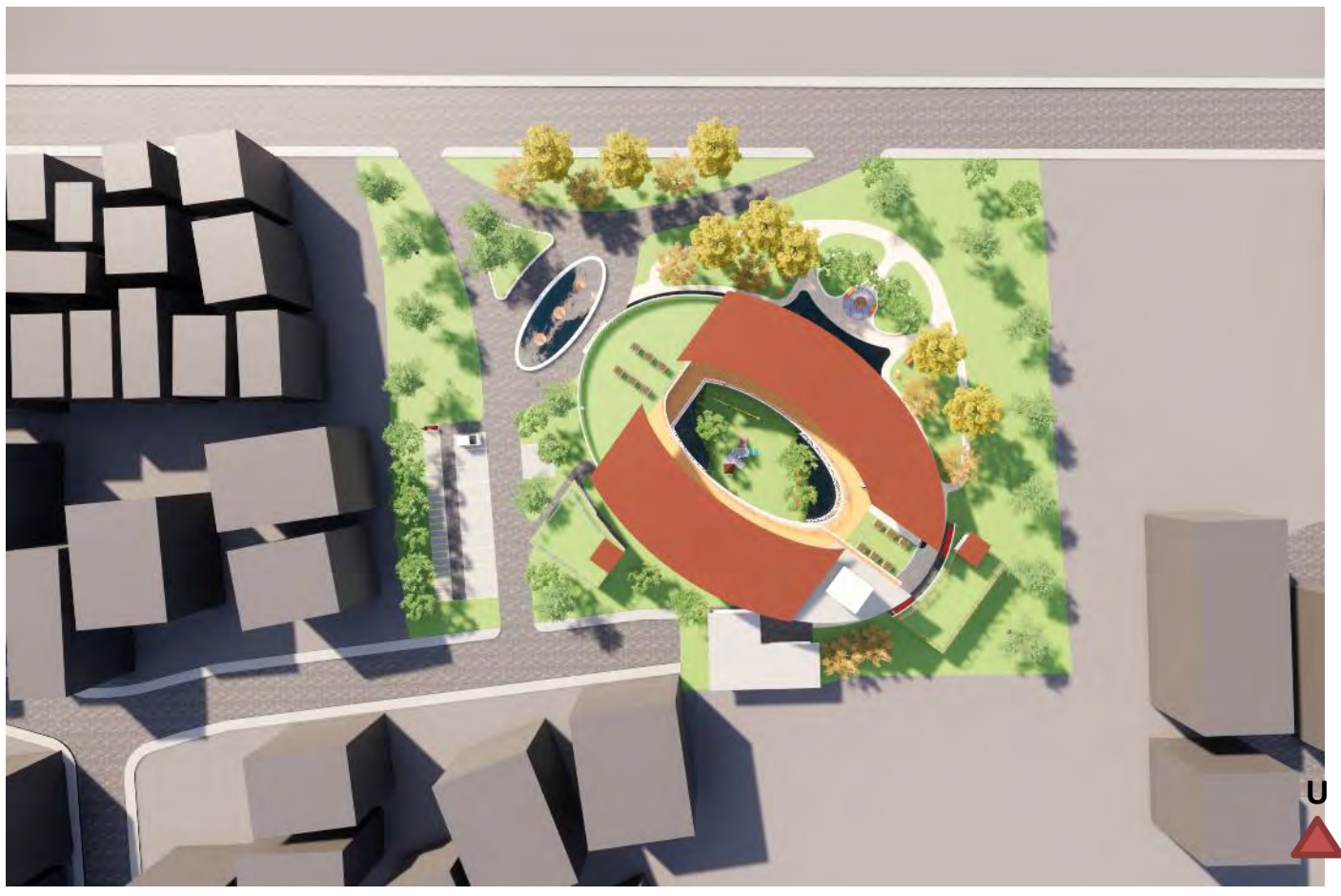

Gambar 10. Tampak Atas Bangunan

Sumber: Penulis, 2020

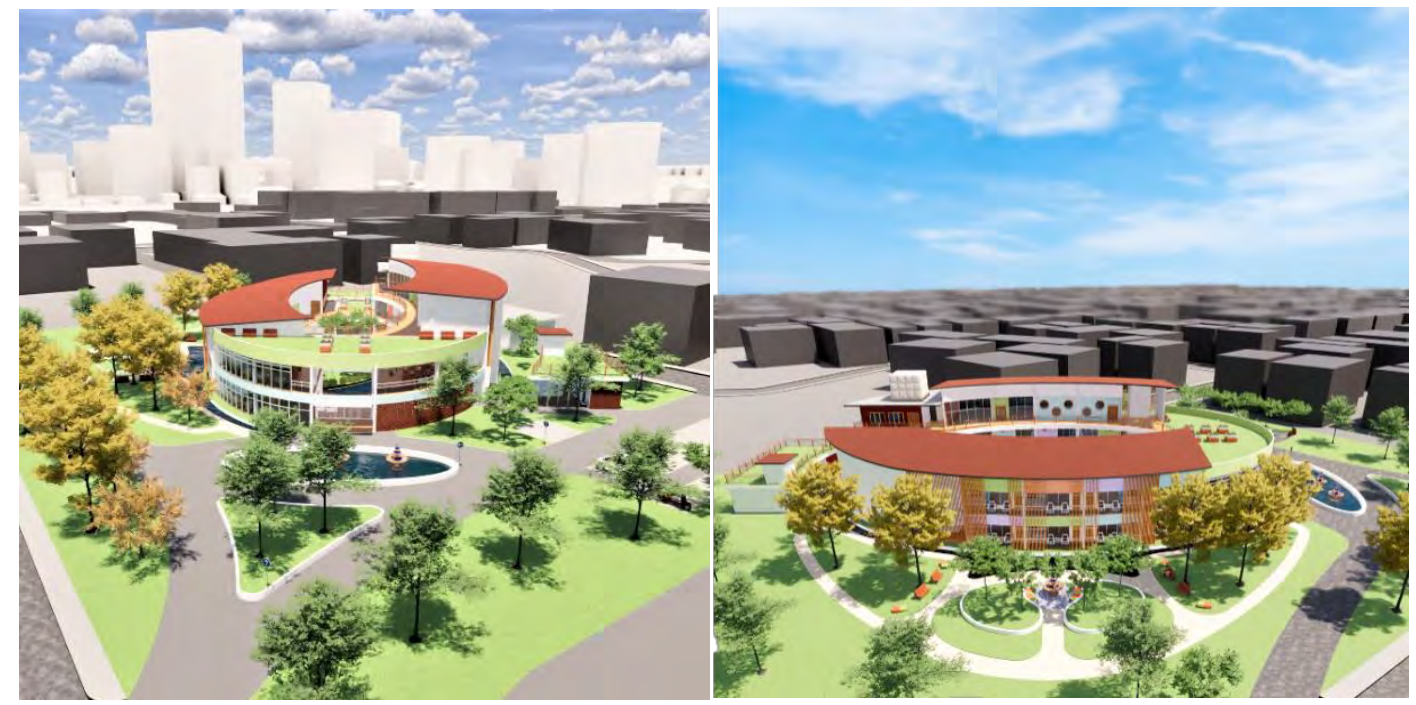

Gambar 11. Tampak Luar Bangunan

Sumber: Penulis, 2020

\section{Program Kegiatan}

Rumah singgah kanker anak ini tidak hanya berfungsi sebagai tempat tinggal alternatif bagi anak-anak penderita kanker yang berasal dari luar kota dan kurang mampu secara ekonomi; namun juga sebagai tempat rekreasi, relaksasi, dan edukasi. Ketiga hal tersebut dinyatakan melalui perawatan paliatif. Fasilitas perawatan paliatif difokuskan ke dalam empat jenis terapi, yaitu: terapi seni, terapi musik, terapi sensorik, dan terapi hewan. 


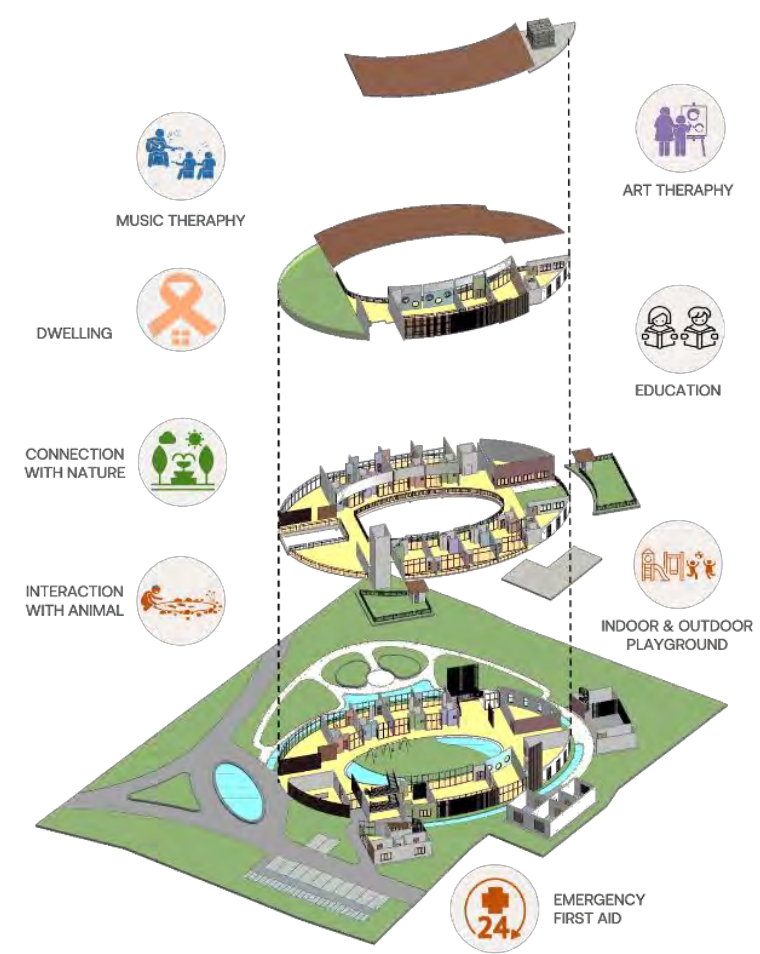

Gambar 12. Program Kegiatan Tapak \& Bangunan Sumber: Penulis, 2020

Terapi seni meliputi kegiatan menggambar/melukis dan membuat kerajinan tangan. Terapi musik meliputi kegiatan memainkan alat musik yang disukai dan menyanyi. Dari kedua terapi tersebut, tidak ada tuntutan tertentu terhadap anak; mereka dapat melakukan kegiatankegiatan tersebut sebagai penyaluran hobi atau sebagai sarana edukasi sesuai kemampuan mereka. Kedua fasilitas terapi berada di lantai 3 karena merupakan fasilitas semi-privat yang hanya ditujukan bagi penghuni dan untuk menghindari kebisingan yang dihasilkan oleh kegiatan terapi tersebut dari zona hunian.

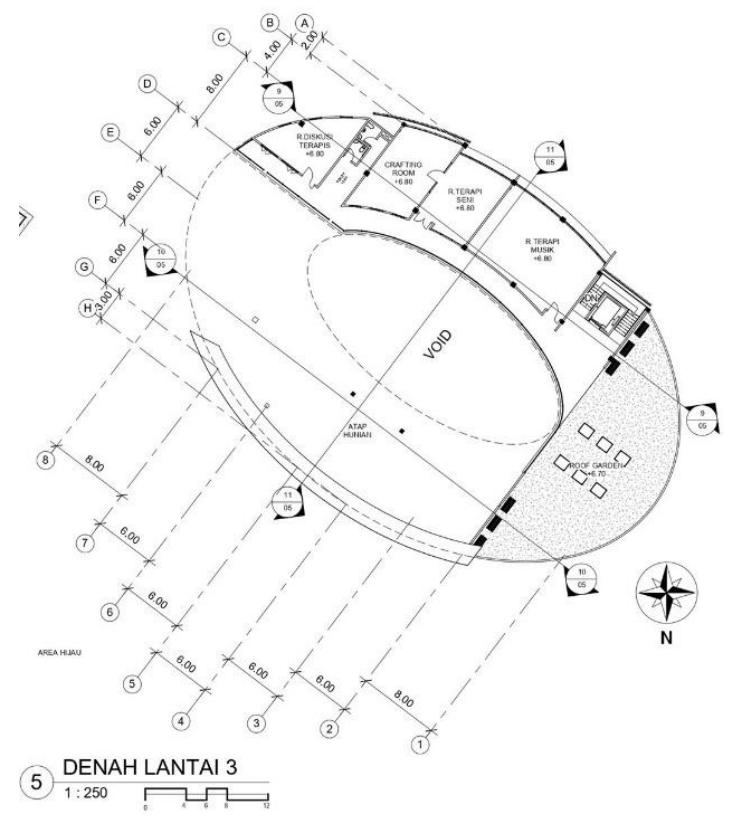

Gambar 13. Denah Lantai 3

Sumber: Penulis, 2020 


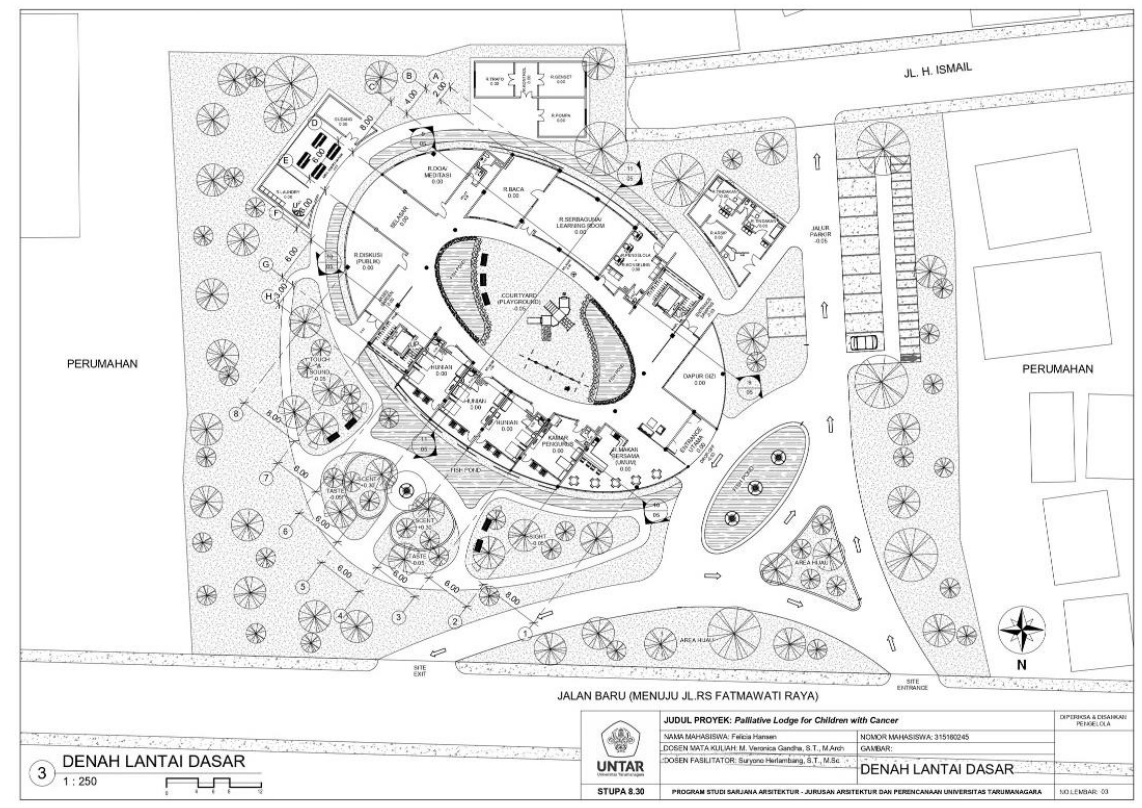

Gambar 14. Denah Lantai Dasar

Sumber: Penulis, 2020

Terapi sensorik meliputi kegiatan interaksi anak-anak dengan berbagai tumbuhan di Taman Sensorik yang dapat merangsang panca indera mereka sekaligus memberi efek relaksasi. Tumbuhan yang memiliki tekstur unik dapat merangsang indera peraba anak-anak. Tumbuhan yang dapat menghasilkan bunyi dapat merangsang indera pendengaran anak-anak. Tumbuhan yang dapat dikonsumsi, seperti buah-buahan, dapat merangsang indera pengecap anak-anak. Tumbuhan yang harum, seperti bunga-bungaan, dapat merangsang indera penciuman anakanak. Tumbuhan yang memiliki bunga dengan warna-warna cerah dapat merangsang indera penglihatan anak-anak. Fasilitas terapi tersebut berada di lantai dasar dan menghadap ke unit hunian, tujuannya agar Taman Sensorik tersebut dapat menjadi pemandangan bagi para penghuni rumah singgah kanker anak dari teras/balkon hunian mereka. Selain itu, posisinya yang dapat terlihat dari pintu masuk tapak dapat menarik pengunjung untuk datang ke taman tersebut juga.

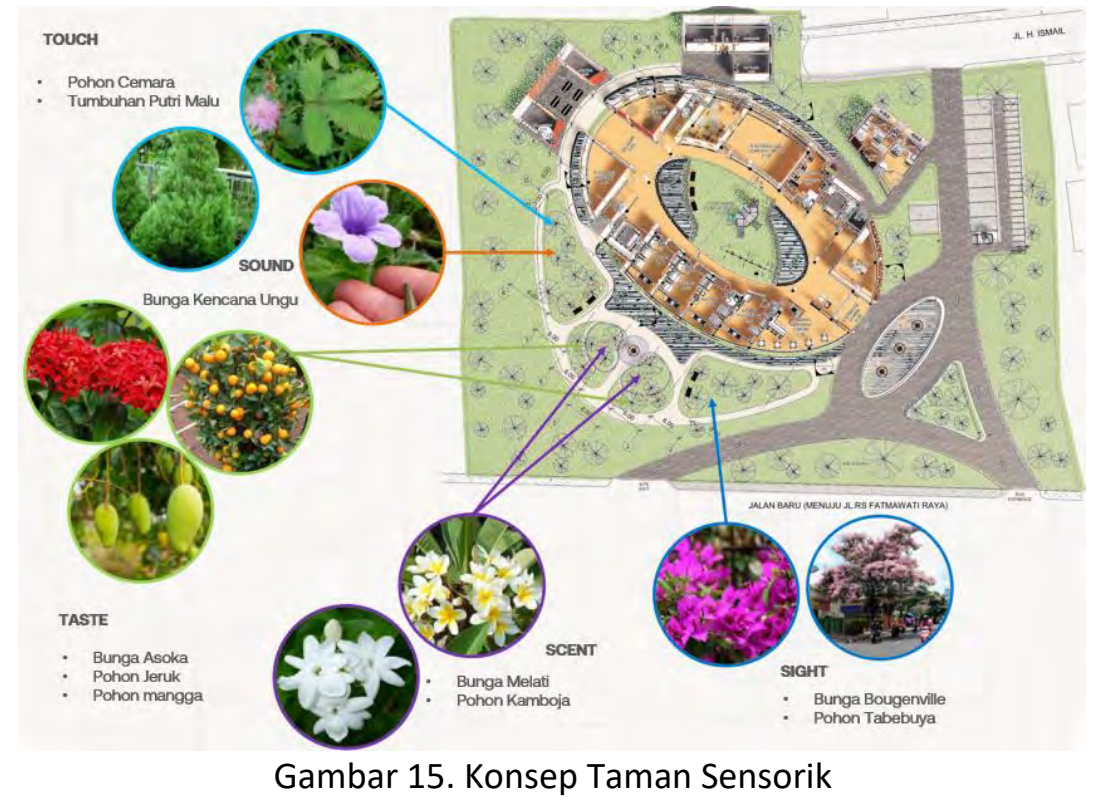

Sumber: Penulis, 2020 
Terapi hewan meliputi kegiatan interaksi anak-anak dengan berbagai ikan hias yang berada di kolam sekitar bangunan dan courtyard. Anak-anak dapat memberi makan ikan-ikan ketika mereka sedang bermain di courtyard dan di Taman Sensorik yang terletak di lantai dasar. Kolam-kolam tersebut juga terdapat di sekeliling bangunan dan bundaran jalur kendaraan. Kolam-kolam ikan ini juga berfungsi sebagai penyejuk lingkungan karena sifat air yang dapat menurunkan suhu lingkungan, sekaligus menambah estetika dan kesan natural pada bangunan.

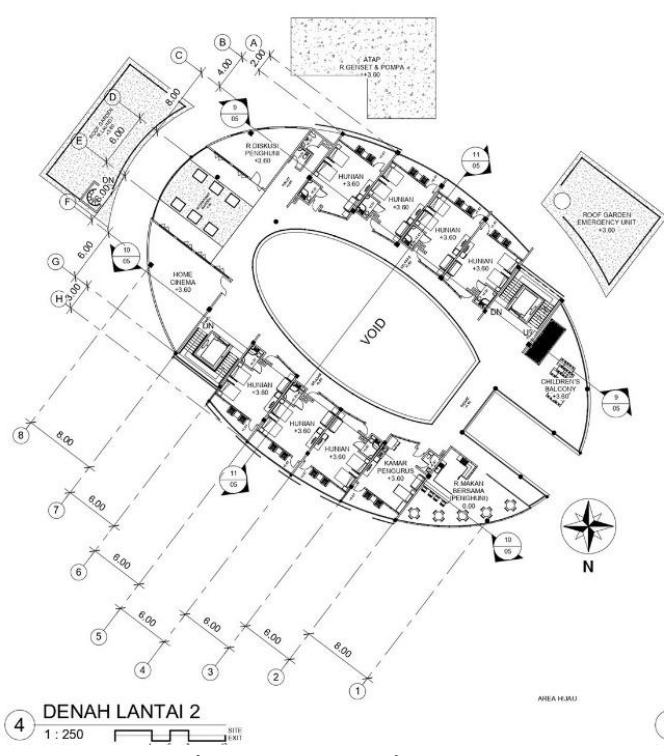

Gambar 16. Denah Lantai 2 Sumber: Penulis, 2020

Selain courtyard dan Taman Sensorik, anak-anak juga dapat bermain di area Children's Balcony yang terletak di lantai 2. Fasilitas tersebut berada di lantai 2 karena merupakan fasilitas semiprivat yang hanya ditujukan bagi penghuni (lantai 2 merupakan area yang dikhususkan sebagai zona hunian). Lantai dasar merupakan zona pertemuan penghuni dengan pengunjung; terdapat zona hunian dan fasilitas bersama di dalamnya. Di lantai dasar juga terdapat fasilitas klinik darurat bagi penghuni. Letaknya yang berada di antara bangunan utama dan area parkir, memudahkan penghuni untuk mendapat pertolongan dari staff medis dan segera membawa kendaraan menuju rumah sakit jika diperlukan.

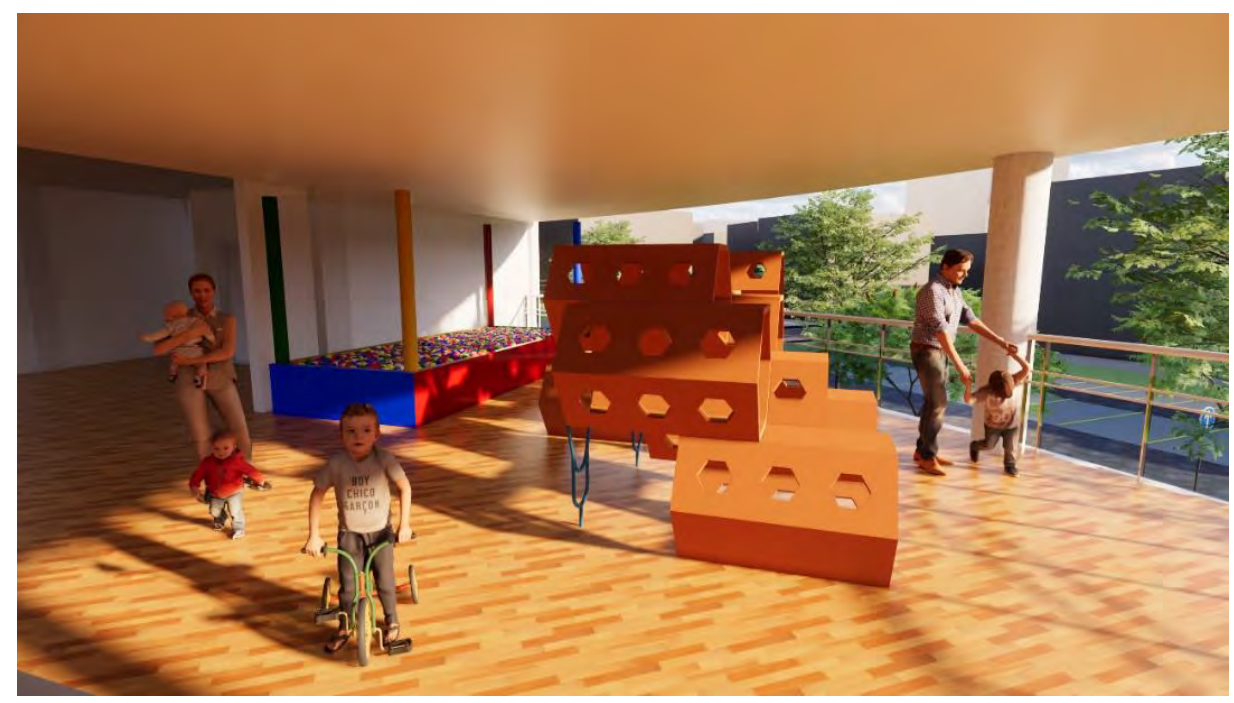

Gambar 17. Children's Balcony

Sumber: Penulis, 2020 


\section{KESIMPULAN DAN SARAN}

\section{Kesimpulan}

Untuk menjawab persoalan pada anak-anak penderita kanker yang berasal dari luar daerah dan keluarganya tidak mampu membiayai rawat inap di rumah sakit, sehingga mereka terpaksa melakukan perjalanan pulang pergi yang memakan banyak waktu dan biaya transportasi; maka dibutuhkan sebuah rumah singgah yang biaya sewanya murah namun dapat mendukung pemulihan dan letaknya dekat dengan rumah sakit. Untuk mendukung pemulihan pada anak-anak penderita kanker, maka diperlukan fasilitas perawatan paliatif; yang dapat memberikan dukungan spiritual dan psikososial. Tapak yang dipilih berada di dekat RSUP Fatmawati; karena di sekitar rumah sakit tersebut belum terdapat rumah singgah kanker untuk umum maupun khusus anak-anak. Perancangan rumah singgah kanker anak ini menggunakan metode desain Arsitektur Keseharian dan Force-based Framework dari Agustinus Sutanto dan Philip Plowright. Dengan kata lain, perancangan rumah singgah kanker ini didasari oleh kebutuhan ruang-ruang baru untuk anak-anak penderita kanker dalam menjalani kegiatan sehari-hari dan bagaimana mereka akan menggunakannya. Selain itu, keterkaitan aktivitas penghuni dengan lingkungannya juga menjadi dasar ide perancangan rumah singgah kanker anak. Adapun program kegiatan yang dimasukkan ke dalam perancangan, yaitu: kegiatan berhuni, koneksi dengan alam, interaksi dengan hewan, kegiatan bermain di luar dan dalam ruangan, terapi seni dan musik, kegiatan edukasi, dan klinik darurat bagi penghuni. Melalui perancangan ini, diharapkan rumah singgah kanker anak ini dapat berguna tidak hanya sebagai tempat tinggal alternatif; namun juga dapat menjadi sarana rekreasi, relaksasi, dan edukasi yang membantu pemulihan bagi anak-anak penderita kanker.

\section{Saran}

Penulis berharap dengan ide perancangan ini, kesadaran masyarakat dan pemerintah akan pentingnya sebuah desain rumah singgah kanker yang dapat membantu pemulihan penghuninya serta kebutuhan perawatan paliatif bagi para penderita kanker dapat meningkat.

\section{REFERENSI}

Antoniades, C. A. (1990). Poetics Of Architecture. New York: Van Nostrand Reinhold Co.

Fricke O.P.; Halswick D.; Langler A.; Martin D.D. (2020). Healing architecture for sick kids: Concepts of environmental and architectural factors in child and adolescent psychiatry. Zeitschrift fur Kinder- und Jugendpsychiatrie und Psychotherapie, 47(1). 27-33

Gola, Marco, Paolo Carlo Francalanza, Giulio Galloni, Bianca Pagella, \& Stefano Capolongo. (2016). Architectures for paediatric palliative care: how to improve quality of life and environmental well-being. Ann Ist Super Sanità, 52(1), 48-55.

Heidegger, M. (1971). Building, Dwelling, Thinking. New York: Harper Colophon Books.

Jencks, C. (2015). The Architecture of Hope: Maggie's Cancer Caring Centres. London: Frances Lincoln.

Norberg-Schulz, C. (1985). The Concept of Dwelling: On the Way to Figurative Architecture. New York: Rizzoli.

Plowright, P. D. (2014). Revealing Architecture: Methods, Frameworks and Tools. New York: Routledge.

Sharr, A. (2007). Heidegger for Architects. New York: Routledge.

Simonds, J. (1961). Landscape Architecture. New York: McGraw Hill Co.

Sutanto, A. (2020). Peta Metode Desain. [Electronic version]. Jakarta: Universitas Tarumanagara

Sutanto, A, dan Andani, A.. (2020). Strategi Komposisi Massa. [Electronic version]. Jakarta: Universitas Tarumanagara 
Verderber, S., dan Ben J. R. (2006). Innovations in Hospice Architecture. [Electronic version]. New York: Taylor \& Francis.

Verderber, S. (2014). Residential Hospice Environments: Evidence-based architectural and landscape design considerations. Journal of Palliative Care, 30(2), 69-82.

Detik Health. (2012). Rumah Singgah Kanker, Rumah Kedua Bagi Pasien Kanker Tak Mampu. Diakses 6 Agustus 2020, dari https://health.detik.com/ulasan-khas/d-1952387/rumahsinggah-kanker-rumah-kedua-bagi-pasien-kanker-tak-mampu

Gould, Rachel. (2017). How Architecture Plays a Role in Bringing Hope to Cancer Patients. Diakses 24 Agustus 2020, dari https://medium.com/the-omnivore/how-architectureplays-a-role-in-bringing-hope-to-cancer-patients-a33aa223015

Kementrian Kesehatan Republik Indonesia. (2019). Hari Kanker Sedunia 2019. Diunduh 10 Agustus 2020, dari https://www.kemkes.go.id/article/view/19020100003/hari-kankersedunia2019.html

Knecht, Michael L. (2010). Optimal Healing Environments. Healthy Communities by Design : Redlands and Loma Linda, CA. Diunduh 2 Agustus 2020, dari https://proceedings.esri.com/library/userc\%20onf/healthy\%20communities10/pdfs/opt imalhealingenvironments.pdf.

Manafe, Dina. (2019). Prevalensi Kanker di Indonesia Meningkat. Diunduh 2 Agustus 2020, dari https://www.beritasatu.com/kesehatan/535688-prevalensi-kanker-diindonesiameningkat

Medina, Samuel. (2014). Architecture Gives Cancer Patients Care Courage. Diakses 24 Agustus 2020, dari https://www.metropolismag.com/architecture/healthcarearchitecture/architecturegives-cancer-patients-care-courage/

Organisasi Lawan Kanker. (2016). Daftar Rumah Singgah Kanker di Indonesia. Diakses 13 Agustus 2020, dari https://lawankanker.org/daftar-rumah-singgah-kanker-di-indonesia/

Puji, Aprinda. (2020). Kanker. Diakses 9 Agustus 2020, dari https://hellosehat.com/kanker/pengertian-kanker/

Sihombing, Rosmery. (2019). Semangat Sembuh dari Rumah Singgah. Diakses 23 Agustus 2020, dari https://mediaindonesia.com/read/detail/230159-semangat-sembuh-darirumahsinggah

Tomboc, Kai. (2019). Cancer in Children Facts and Statistics: A Visual Case Study. Diunduh 2 Agustus 2020, dari https://www.easel.ly/blog/cancer-in-children-infographics/

World Health Organization. (2018). Cancer in Children. Diunduh 2 Agustus 2020, dari https://www.who.int/news-room/fact-sheets/detail/cancer-in-children 
